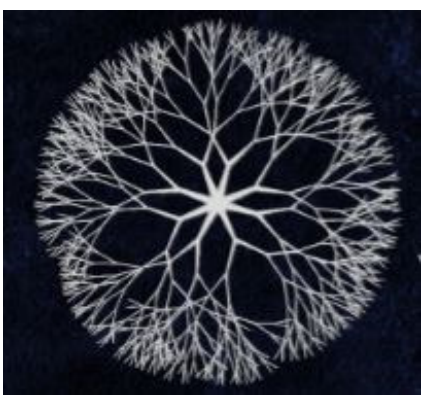

Dossiê - Simpósio USP "Construindo diálogos interdisciplinares"

\title{
Mary Montagu e a inoculação da varíola na Inglaterra no século XVIII
}

\author{
Marina Juliana de Oliveira Soares \\ Pós-doutora em História da Medicina do período Moderno \\ USP - FFLCH \\ oliveiras.mari@gmail.com
}

Recebido em 17/01/2018. Aprovado em 03/04/2018.

Como citar este artigo: Soares, Marina Juliana de Oliveira.; "Mary Montagu e a inoculação da varíola na Inglaterra no século XVIII”. Khronos, Revista de História da Ciência, no5, p. 35-46. 2018. Disponível em <http://revistas.usp.br/khronos>. Acesso em dd/mm/aaaa.

Resumo: Quando pesquisamos o tema da inoculação na Inglaterra, encontramos menção a mais nomes masculinos do que à mulher com papel de destaque na disseminação desse procedimento. Trata-se de Mary Wortley Montagu (1689-1762), escritora e defensora desse método que ela conheceu no Império Otomano. Diante do pouco destaque concedido a ela nesse capítulo da história da medicina, a proposta desse artigo é apresentar a figura de Montagu, a sua história pessoal com a varíola, sua defesa do procedimento de inoculação na Inglaterra e a forte oposição sofrida por ela. Dentre os opositores, figuravam membros da Royal Society e do College of Physicians, em cujos argumentos destacavam-se juízos depreciativos sobre o Levante e um forte teor sexista.

Palavras-chave: Mary Montagu, inoculação, varíola, gênero, orientalismo.

\section{Mary Montagu and inoculation of smallpox in England in the XVIII century}

\begin{abstract}
When we investigate the issue of inoculation in England, it is common to find mention of more male names than a woman with a prominent role in the dissemination of this procedure. This is Mary Wortley Montagu (1689-1762), writer and advocate of this method she met in the Ottoman Empire. In the light of the little emphasis given to her in this chapter of the history of medicine, the proposal of this article is to present the figure of Montagu, her personal history with smallpox, her defense of inoculation procedure in England, and the strong opposition suffered by her. Opponents included members of the Royal Society and the College of Physicians, in whose arguments were present derogatory judgments about the Levant and a strong sexist content.
\end{abstract}

Keywords: Mary Montagu, inoculation, smallpox, gender, orientalism. 


\section{A varíola}

A varíola era conhecida dos europeus desde o início do período medieval ${ }^{1}$ e tinha as origens remetidas ao "clima demasiado quente do norte da África" de onde os "invasores islâmicos" a teriam transportado para a Europa ${ }^{2}$. A doença, cuja causa é atualmente atribuída a um vírus, era considerada à época como sendo transmitida através do contato com "descargas respiratórias, lesões da pele e das mucosas" de pessoas contaminadas ${ }^{3}$. Embora desconhecessem nesse momento o agente causador da doença, os europeus acreditavam que os surtos de varíola eram ocasionados por "uma 'matéria' específica, reproduzível”4, que derivava tanto das pústulas quanto do miasma ${ }^{5}$ emitido pelo doente ${ }^{6}$.

Durante o período moderno, os surtos da doença eram frequentes. De acordo com pesquisadores atuais, entre $25 \%$ e $50 \%$ da população teriam sido atingidas pela varíola nos séculos XVII e XVIII7. No começo do século XVII, a taxa de mortalidade da doença "cresceu significativamente" 8 . No caso da Inglaterra, a varíola foi marcadamente presente no fim do século XVII e na primeira metade do século XVIII ${ }^{9}$. Em Londres, a doença era endêmica: no século XVII, ocorria aproximadamente a cada quatro anos; já no século seguinte, os surtos se sucediam a cada dois anos ${ }^{10}$.

O termo em inglês para a varíola - smallpox - "apareceu na Inglaterra no início do século XVI como correspondente ao termo francês la petite vérole; este era usado para marcar a distinção em relação a outra doença, a grosse vérole, ou seja, a sífilis ${ }^{11}$. A concepção corrente sobre a manifestação da doença era de que ela atingia principalmente os bebês e as crianças. No caso de crianças mais velhas e adultos, a infecção era considerada frequentemente fatal ${ }^{12}$.

Não havia concordância na classe médica sobre as causas da doença, mas havia um consenso sobre o "processo da doença". A explicação se dava nos seguintes termos: a "matéria mórbida da varíola" era formada no sangue por meio da "combinação de fluidos corporais e matéria infecciosa ou, possivelmente, por um processo de fermentação"13. Depois de separada do sangue durante a febre, ela "viajava para a pele"14. Era isso que formava as manchas. Embora

1 BARNES, D. The public life of a woman of wit and quality: Lady Mary Wortley Montagu and the vogue for smallpox inoculation. Feminist Studies, v. 38, n. 2, p. 330-362, 2012, p. 333.

${ }^{2}$ SHUTTLETON, D. E. Smallpox and the Literary Imagination, 1660-1820. Cambridge: Cambridge University Press, 2007, p. 7.

${ }^{3}$ DOBSON, M. J. Contours of Death and Disease in Early Modern England. Cambridge: Cambridge University Press, 2003, p. 477.

${ }^{4}$ ROSENBERG, C. E. Explaining Epidemics and other Studies in the History of Medicine. Cambridge: Cambridge University Press, 1992, p. 295.

${ }^{5}$ Como defende Jacques Jouanna, a palavra grega miasma não possuía em princípio uma conotação médica. $\mathrm{O}$ uso mais antigo do termo indicava o sangue derramado em virtude de um crime Cf. JOUANNA, J. Greek Medicine from Hippocrates to Galen: Selected Papers. Leiden/Boston: Brill, 2012, p. 121-136. De modo geral, o sentido de miasma compreendia a noção de contaminação do ar, ocasionada por uma variedade de fontes: pântanos estagnados, cadáveres humanos e de outros animais, alimentos estragados, exalações advindas do solo. Esse estado de putrefação do ar foi usado para explicar a disseminação de doenças desde então. Sobre isso, ver BYNUM, W. F.; PORTER, R. (ed.). Companion Encyclopedia of the History of Medicine. Volume 1. London/New York: Routledge, 1993, p. 295.

${ }^{6}$ BRUNTON, D. Pox Britannica: Smallpox Inoculation in Britain, 1721-1830. Tese de Doutorado, Philadelphia: University of Pennsylvania, 1990, p. 46 [http://repository.upenn.edu/edissertations/999]

7 BARNARD, T. (ed.). British women and the intellectual world in the long eighteenth century. New York: Routledge, 2015, p. 1819.

${ }^{8}$ BARNES, 2012, op. cit. p. 333.

${ }^{9}$ BARNES, 2012, op. cit. p. 477.

${ }^{10}$ BARNES, 2012, op. cit. p. 333.

${ }^{11}$ ROSEN, G. A History of Public Health. Revised Expanded Edition. Baltimore: JHU Press, 2015, p. 48.

${ }_{12}^{12}$ ROSEN, 2015, op. cit. p. 48.

${ }^{13}$ BRUNTON, 1990, op. cit. p. 12.

${ }^{14}$ BRUNTON, 1990, op. cit. p. 12. 
os médicos apontassem sintomas variados dessa doença - mais de vinte eram indicados ${ }^{15}$-, é certo que as pústulas eram os sinais característicos da varíola. Além das cicatrizes na pele, as consequências dessa enfermidade podiam compreender cegueira, deformidades nos membros e aumento da suscetibilidade em ser acometido por outras doenças, como a tuberculose ${ }^{16}$.

O chamado "método quente" de Richard Morton (1637-1698) era a "forma mais comum de tratamento" 17 no fim do século XVII. Segundo esse método, os pacientes deveriam ficar num cômodo quente, bem cobertos, com a intenção de provocar suores no corpo, o que expulsaria a matéria da varíola. Na década de 1660, o debate se intensificou, pois "Thomas Sydenham adotou teorias corpusculares para argumentar por um inovador "método frio""18. Nessa nova concepção de tratamento, "sangria, purgações e eméticos, bebidas frias e exposição ao ar fresco eram usados para regular a circulação e remover a matéria mórbida"19. Embora na década de 1720 houvesse uma tendência dos escritores em se opor ao uso de mercúrio e antimônio contra essa doença, atrelada à crença na homogeneidade da manifestação da varíola, ainda assim havia espaço para os tratamentos assentados nas características particulares de cada paciente ${ }^{20}$.

\section{A história pessoal de Mary Montagu com a varíola e a inoculação}

Mary Wortley Montagu - cujo sobrenome de solteira era Pierrepont - nasceu na Inglaterra em 1689 e faleceu no mesmo país em 1762. De origem nobre, pode se dedicar à vida intelectual a partir de seu próprio empenho, ou seja, de forma autodidata ${ }^{21}$. Daí o extenso conjunto de cartas, poesias e textos em prosa produzidos por ela ${ }^{22}$. Tais produções, contudo, não eram conhecidas além de seu círculo de amizades e foram publicadas de forma anônima - como o artigo sobre a inoculação, de 1722, que será mencionado adiante. Nas últimas décadas, vimos o adensamento de pesquisas acerca da produção literária de Montagu, de suas reflexões sobre o Levante $^{23}$, de suas contribuições ao papel social das mulheres e também de sua defesa do método de inoculação na Inglaterra. É possível afirmar que esse último tópico mantém uma ligação estreita com os anteriores, uma vez que a inoculação trouxe à tona posicionamentos hostis de autores europeus sobre o Império Otomano e sobre a função pública das mulheres na área médica.

A varíola não era apenas um tema de interesse intelectual para Montagu; essa doença foi sentida por ela de forma prática. O primeiro golpe veio com a morte de um irmão seu, em 1713, em decorrência da enfermidade. Em dezembro de 1715, ela própria foi atingida pela varíola. Depois de fortes dores de cabeça, vômitos e sede terrível, as manchas na pele surgiram no terceiro $\mathrm{dia}^{24}$. As manchas se tornaram pústulas e se espalharam pelo corpo. Um de seus médicos, Samuel Garth, havia demonstrado otimismo quanto à recuperação de seu irmão ${ }^{25}$. Contudo, em

\footnotetext{
15 Ver BARNARD, 2015, op. cit. p. 19.

${ }^{16}$ BARNARD, 2015, op. cit. p. 20.

${ }^{17}$ BRUNTON, 1990, op. cit. p. 12-13.

${ }^{18}$ CARLIN, C. L. (ed.). Imagining contagion in Early Modern Europe. Basingstoke: Palgrave Macmillan, 2005, p. 240.

${ }^{19}$ BRUNTON, 1990, op. cit. p. 13.

${ }^{20}$ Deborah Brunton discute como os médicos se baseavam nas características individuais dos pacientes para encaminhar os tratamentos, além de apontar a ascensão de "métodos padronizados", ver BRUNTON, 1990, op.cit., em particular o capítulo 2, p. 42-66.

${ }^{21}$ GRUNDY, I. Lady Mary Wortley Montagu: Comet of the Enlightenment. Oxford: Oxford University Press, 1999, p. xvii.

22 Sobre as publicações de Mary Montagu, em especial sobre o gênero epistolar, ver LOWENTHAL, C. J. Lady Mary Wortley Montagu and the Eighteenth-Century Familiar Letter. Athens/London: The University of Georgia Press, 2010.

${ }^{23}$ Durante o século XVIII, o termo "Oriente" era pouco usado pelos viajantes europeus para se referir às regiões de domínio islâmico; "Levante", ou mesmo "Turquia", eram empregados com mais frequência.

${ }^{24}$ GRUNDY, 1999, op. cit. p. 99.

${ }^{25}$ Isobel Grundy aponta Richard Mead e John Woodward como os outros médicos que atenderam Montagu nesse período, op. cit. p. 100. Já Robert Halsband cita Hans Sloane ao lado de Samuel Garth, ver HALSBAND, R. New
} 
virtude do desfecho trágico de 1713, Lady Mary revelou incredulidade acerca de sua própria recuperação ${ }^{26}$. Embora notícias de seu restabelecimento ocorressem em janeiro de 1716, as consequências da doença foram perenes: "seus cílios nunca voltaram a crescer, ela sofreu infecções oculares recorrentes pelo resto de sua vida e, como todos os sobreviventes, as pústulas cheias de líquido causadas pelo vírus deixaram cicatrizes permanentes na pele quando irromperam e secaram"27. Nos anos seguintes, Lady Mary testemunharia mais surtos de varíola e outras mortes de amigos e familiares ocasionadas pela doença, como veremos.

Diante desse cenário, o tema da varíola e as possibilidades de combater essa doença fariam parte do interesse corrente de Montagu. No período em que vivenciou a enfermidade, ela escreveu um poema, dentro de um conjunto de seis idílios, no qual refletia sobre os efeitos da doença ${ }^{28}$. Nestes versos, Lady Mary apresentava a personagem Flavia, que havia sido atingida pela varíola. Um dos temores de Flavia se referia à perda da beleza, que - ela assegurava - não poderia ser restaurada, fosse pelas roupas ou pelos $\operatorname{cosméticos}^{29}$. É certo que o lamento de Flavia poderia ser a expressão do próprio pesar de Mary Montagu, mas havia nos versos um tom crítico em relação a esse tema. Para Jennifer Keith, a poeta demonstra um equilíbrio entre "a simpatia por Flavia e a condenação da vaidade da beleza física"30. De todo modo, o tema da perda da beleza em decorrência das cicatrizes deixadas pela doença era frequente, e particularmente sensível para as mulheres.

Foi no ano de sua recuperação que Mary Montagu iniciou uma jornada que a levaria ao conhecimento de um novo método de combate à doença. Em virtude do apontamento de seu marido, Edward Montagu, como embaixador no Império Otomano, Lady Mary pôde entrar em contato com um método desconhecido na Inglaterra, realizado por grupos de senhoras em terras turcas: a inoculação ou enxerto. Importante considerar que a escritora inglesa teria encontrado o método não "por acaso, mas porque ela estava procurando", como alerta Isobel Grundy ${ }^{31}$.

Não é possível precisar se Mary Montagu possuía qualquer informação sobre a inoculação da varíola antes de sua viagem para o Levante, iniciada em agosto de 1716. De todo modo, há um elemento que levanta suspeitas sobre esse conhecimento prévio. A autora inglesa possuía contato próximo com médicos filiados à Royal Society e, portanto, poderia ter ciência da publicação de artigos sobre o tema no periódico dessa Sociedade, o Philosophical Transactions. Os textos dos médicos residentes em Constantinopla, Emmanuel Timoni e Jacob Pilarini, haviam sido publicados no volume 29, com datação em $1^{\circ}$ de janeiro de $1714^{32}$. Antes disso, em 1700, o médico Clopton Havers apresentava à Royal Society seu relato sobre o método de inoculação chinês, que consistia na inalação em pó das cicatrizes retiradas dos acometidos pela varíola33.

Light on Lady Mary Wortley Montagu's Contribution to Inoculation. Journal of the History of Medicine and Allied Sciences, v. 8, n. 4, p. 390-405, 1953, p. 392.

${ }^{26}$ HALSBAND, 1953, op. cit. p. 392.

${ }^{27}$ GREY, D. J. R. 'To bring this useful invention into fashion in England': Mary Wortley Montagu as Medical Expert. In: BARNARD, T. (ed.). British Literature in Context in the Long Eighteenth Century. London/New York: Routledge, 2015, p. 22.

${ }^{28}$ Por volta de 1716, após se recuperar da doença, Mary Montagu escreveu um idílio intitulado "Satturday: The Small Pox”, um poema que concluía o Six Town Eclogues. Sobre isso, ver BARNES, 2012, op. cit. p. 339-341.

${ }^{29}$ Ver BARNARD, 2015, op. cit. p. 23.

${ }^{30}$ KEITH, J. Lady Mary Wortley Montagu (1689-1762): Haughty Mind, Warm Blood and the 'Demon of Poesie'. In: PRESCOTT, S.; SHUT'TLETON, D. E. (ed.). Women and Poetry, 1660-1750. Basingstoke: Palgrave Macmillan, 2003, p. 81.

${ }^{31}$ GRUNDY, 1999, op. cit. p. 144.

32 Sobre os artigos, ver ROYAL SOCIETY. Philosophical Transactions, v. 29, 1714-1716, p. $72-82$ e 393-399, respectivamente.

${ }^{33}$ BRUNTON, 1990, op. cit. p. 13. 
Afora esses artigos, em 1715, o cirurgião escocês Peter Kennedy publicava o seu Essay on External Remedies, em que dedicou um capítulo sobre o enxerto da varíola ${ }^{34}$.

Lady Mary, assim como os médicos Timoni e Pilarini, teve contato com a prática da inoculação no Império Otomano. Dado o entusiasmo com o procedimento, a escritora inglesa mencionou o assunto em uma das cartas escritas durante o período em que esteve no Levante, e que foram publicadas sob o título Turkish Embassy Letters em 1763. Trata-se da "Carta XXXI" inserida no volume II da primeira edição. O texto foi escrito em Adrianópolis [atual Edirne] em 1717, com destino a uma amiga de Montagu, Sarah Chiswell.

Ao iniciar o tema dessa doença na Carta, Montagu afirmava: "A varíola, tão fatal e tão comum entre nós, é inteiramente inofensiva aqui, pela invenção do enxerto, que é o termo que eles usam"35. A operação era empreendida por senhoras que a realizavam "a cada outono, no mês de Setembro" 36. Tais senhoras extraíam o que a autora chamou de "matéria do melhor tipo de varíola" daqueles acometidos pela doença, em seguida, guardavam-na numa casca de noz e perguntavam àquele que seria inoculado qual veia deveria ser aberta para receber a matéria. $\mathrm{O}$ procedimento era realizado em quatro ou cinco veias por meio de uma agulha, cuja dor provocada não era maior do que um "arranhão". Depois disso, Montagu limitava-se a afirmar que o ferimento era fechado com um pedaço da própria casca de noz. Aqueles que se submetiam à técnica preferiam fazê-la na perna ou em alguma parte do braço que poderia ficar escondida. Tanto crianças quanto adultos voltavam à "perfeita saúde" em oito dias ${ }^{37}$.

Ainda que esse seja o único momento das "Cartas" em que Lady Mary citou o procedimento, é possível que a discussão sobre o método ou mesmo o testemunho de outro episódio da inoculação tenham ocorrido mais de uma vez. Lembremos a esse respeito que o citado médico Emmanuel Timoni prestou seus serviços à família Montagu no período em que esta esteve em Constantinopla, onde ele afirmava ter presenciado oito anos de inoculação da varíola ${ }^{38}$. O fato é que ela ficou tão impressionada com o método que resolveu primeiro inocular seu filho, em 1718, e, depois, defender seu uso na Inglaterra.

Lady Mary tinha consciência de que se tratava de um experimento - ela própria empregou o termo em sua carta -, contudo, apegou-se à informação de que ninguém havia morrido em razão do método ${ }^{39}$. Diante disso, ela decidiu pela inoculação de seu filho mais velho, Edward, com cerca de cinco anos de idade. O procedimento de inoculação era realizado por mulheres mais velhas. No caso de Edward, uma senhora grega havia iniciado a operação em um de seus braços, porém, como as suas mãos trêmulas e a "agulha frouxa e enferrujada" tinham provocado dor no menino, foi necessária a intervenção de um cirurgião, nesse caso, o escocês Charles Maitland (1668-1748), que inoculou o outro braço da criança. Maitland era o cirurgião que prestava serviços na embaixada britânica em terras turcas, e responsável por relatar esse episódio em obra originalmente publicada em $1722^{40}$.

\footnotetext{
${ }^{34}$ Ver Capítulo XXXVII. In: KENNEDY, P. An Essay on External Remedies. London: Printed for Andrew Bell, 1715, p. 153-157.

${ }^{35}$ MONTAGUE, M. Letters of the Right Honourable Lady $M_{-} y$ W_y M_e: written during her Travels in Europe, Asia and Africa. Volume I/II. London: Printed for T. Becket and P. A. de Hondt, 1763, p. 59-60.

${ }^{36}$ MONTAGUE, 1763 , p. 60.

${ }^{37}$ MONTAGUE, 1763 , p. 61.

${ }^{38}$ Ver TIMONIUS, E.; WOODWARD, J. An Account, or History, of the Procuring the Small Pox by Incision, or Inoculation; As It has for some time been practised at Contantinople. In: ROYAL SOCIETY, Philosophical Transactions, v. 29, 1714-1716, p. 72.

${ }^{39}$ MONTAGUE, 1763, op. cit. p. 62.

${ }^{40}$ MAITLAND, C. Mr. Maitland's Account of Inoculating the Small Pox. 2nd edition. London: J. Peele, 1723, p. 7.
} 
Após a operação, o filho de Montagu se recuperou bem e, apesar das muitas manchas no corpo - teriam sido mais de cem -, nenhuma marca havia causado cicatriz na sua pele ${ }^{41}$. Lady Mary informou seu marido sobre a inoculação de Edward em carta escrita em Constantinopla, datada de 23 de março de 1718. Na mensagem, a escritora inglesa afirmava que o filho do casal havia sido "enxertado na última terça-feira" 42 Já a filha mais nova - que havia nascido no Levante - não passara pelo procedimento. Nesse caso, é possível que Lady Mary temesse o contágio da enfermeira da menina, uma vez que essa não havia tido varíola ${ }^{43}$. Em breve, a filha de Montagu também seria submetida à operação, num período marcante das discussões sobre a inoculação da varíola na Grã-Bretanha.

\section{A inoculação "turca" e a controvérsia na Inglaterra}

O uso da inoculação da varíola não possui origens certas. Esse tipo de prática estava se tornando corrente na medicina chinesa durante o século XVI ${ }^{44}$. No caso dos turcos, a técnica teria sido introduzida pelos seljúcidas, que mantinham contato com a Pérsia e com o Oriente Médio desde antes da formação do Império Otomano ${ }^{45}$. O procedimento teria se tornado conhecido no Império Otomano por meio de mercadores circassianos no século XVII ${ }^{46}$. O fato de tal prática ter origens em terras asiáticas estimularia julgamentos valorativos quando a inoculação ganhou defensores na Europa, como será indicado a seguir.

Embora artigos sobre a inoculação da varíola fossem conhecidos na Europa antes da viagem de Montagu ao Império Otomano, foi somente após o seu retorno à Inglaterra que o procedimento passou a ser mais intensamente debatido. É certo que Lady Mary não atuou sozinha nesse processo, mas não há dúvida de que a sua defesa da inoculação - reforçada pela operação realizada na sua filha - foi um evento central no processo de discussão e realização do método na Europa. Sobre isso, Deborah Brunton, para quem há certo exagero no papel atribuído a Montagu nesse episódio, defende a inoculação da filha de Lady Mary como momento essencial para despertar o interesse da classe médica ${ }^{47}$.

O retorno da família Montagu para casa se iniciou em julho de 1718, e a chegada a Londres ocorreu em outubro desse ano. No seu regresso, Montagu viveu pelos menos dois surtos da doença num pequeno intervalo de tempo: em 1719 e em 1721. Foi neste último ano que a autora inglesa resolveu agir para proteger sua filha caçula, Mary, afinal, pessoas próximas - dentre elas, uma jovem prima de dezesseis anos - haviam morrido em decorrência da varíola ${ }^{48}$. Então, em abril de 1721, ela escreveu para o cirurgião Charles Maitland, que estava atuando em Hertford, pedindo a ele que inoculasse sua filha. Maitland declinou do convite inicialmente, pois tinha várias razões profissionais para se opor ao pedido: era cirurgião e escocês, atuava num país estrangeiro - a Inglaterra -, e estaria "sob os olhares do College of Physicians, caso aceitasse realizar

${ }^{41}$ MAITLAND, 1723, op. cit. p. 8.

42 Maitland indicava outra data para o procedimento: março de 1717, em Pera, perto de Constantinopla. Ver MAITLAND, 1723, op. cit. p. 8.

${ }^{43}$ HEFFERNAN, T.; O'QUINN, D. (ed.). The Turkish Embassy Letters. Lady Mary Wortley Montagu. Peterborough: Broadview Editions, 2013, p. 226.

${ }^{44}$ Sobre isso, ver NEEDHAM, J. China and the origins of Immunology. Hong Kong: University of Hong Kong, 1980, p. 1517; e BARNARD, 2015, op. cit. p. 25.

${ }^{45}$ DINC, G.; ULMAN, Y. I. The introduction of variolation 'A La Turca' to the West by Lady Mary Montagu and Turkey's contribution to this. Vaccine, v. 25, n. 21, p. 4261-4265, 2007, p. 4262.

${ }^{46}$ Ibid. p. 4262.

${ }^{47}$ BRUNTON, 1990, op. cit. p. 8.

48 GRUNDY, 1999, op. cit. p. 209 
o procedimento ${ }^{49}$. Ainda que houvesse muitos fatores contrários a tal ação, ele acabou aceitando o pedido.

Para realizar a inoculação, Maitland solicitou à Lady Mary uma espera de uma ou duas semanas, quando o clima estaria "frio e úmido" 50 . Além disso, ele requisitava a presença de "dois médicos quaisquer", não apenas para se assegurarem da "saúde e da segurança da criança", mas, do mesmo modo, para testemunharem a prática, contribuindo, assim, para "o crédito e a reputação" do procedimento ${ }^{51}$. Pelo relato de Maitland, sabemos que o pedido inicialmente foi negado - talvez pelo desejo de Montagu em manter segredo sobre o processo. Ainda com base no texto desse cirurgião, pode-se inferir que a menina recebeu visitas após se submeter à operação. Nesse caso, tratava-se de "três médicos eruditos do College", os quais puderam verificar o seu bom estado de saúde ${ }^{52}$.

Há uma indicação importante feita por Maitland sobre o processo de inoculação da filha de Montagu. O cirurgião não utilizou qualquer preparação prévia - como sangria ou purgação -, alegando que isso não era necessário, dados o "hábito de corpo limpo" e a dieta regular da menina ${ }^{53}$. Embora não seja possível afirmar, essa forma de realizar o procedimento, que se baseava estritamente na experiência de Montagu e Maitland no Império Otomano, poderia ser um pedido da própria escritora inglesa. Nos anos seguintes, Lady Mary se oporia veementemente à forma como os médicos ingleses haviam interferido no método turco, corrompendo-o. Na década de 1720, os cirurgiões e médicos ingleses adotaram a inoculação com uma série de modificações. Além dos preparativos aconselhados a cada paciente, os praticantes substituíram a agulha pela lanceta, faziam "cortes mais largos e mais profundos" 54 , e optavam por manter o ferimento aberto com a intenção de dissipar os humores ${ }^{55}$.

A operação feita na filha de Mary Montagu é considerada a primeira inoculação profissional na Inglaterra ${ }^{56}$. O sucesso obtido nesse procedimento contribuiu, possivelmente, para ampliar o interesse pelo método. Montagu tinha acesso aos círculos aristocráticos da sociedade britânica, e mantinha proximidade com personagens que se empenharam diretamente em experimentos de inoculação. Dentre estes, destacavam-se Hans Sloane, médico que ocupou a presidência tanto do College quanto da Royal Society ${ }^{57}$; a princesa Carolina de Gales; e o rei George I. Diante do aceite de uma petição enviada ao rei - da qual Hans Sloane participou -, uma primeira experiência pública foi realizada em 1721. Em nove de agosto desse ano, seis prisioneiros de Newgate condenados à morte foram submetidos ao procedimento, com a condição de serem libertados caso sobrevivessem. A operação foi executada por Charles Maitland, que verificou o sucesso do procedimento em cinco prisioneiros, já que um deles havia sido contaminado pela varíola no ano anterior e possuía o que hoje chamamos imunidade à doença ${ }^{58}$.

O episódio de Newgate despertou o interesse da princesa Carolina, que demonstrou a intenção de realizar um novo experimento, dessa vez com crianças. O plano inicial era financiar

\footnotetext{
${ }^{49}$ GRUNDY, 1999, op. cit. p. 210.

${ }^{50}$ MAITLAND, 1723, op. cit. p. 9.

51 MAITLAND, 1723, op. cit. p. 9.

52 "they saw Miss Wortley playing about the Room, chearful (sic) and well (...) and that in a few Days after she perfectly recover'd of them" Cf. MAITLAND, 1723, op. cit. p. 10.

${ }^{53}$ MAITLAND, 1723 , op. cit. p. 9.

${ }^{54}$ BRUNTON, 1990, op. cit. p. 25.

55 Para um quadro detalhado de tais mudanças, ver BRUNTON, 1990, op. cit., em especial, o capítulo 2 "A Medical Reformation, 1680-1730", p. 42-65.

${ }^{56}$ GRUNDY, I. Medical Advance and Female Fame: Inoculation and its After-Effects. Lumen: Selected Proceedings from the Canadian Society for Eighteenth-Century Studies, v. 13, p. 13-42, 1994, p. 16.

${ }^{57}$ Hans Sloane foi eleito presidente do College of Physicians em 1719, permanecendo no posto até 1735 . Ocupou também a função de presidente da Royal Society entre 1727 e 1741 Cf. DELACY, M. The Germ of an Idea: Contagionism, Religion, and Society in Britain, 1660-1730. Basingstoke: Palgrave Macmillan, 2016, p. 67.

${ }^{58}$ Charles Maitland descreve o experimento em Newgate na edição de 1723, ver op. cit. p. 20-26.
} 
a inoculação de “todas as crianças órfãs” que viviam na paróquia de St. James, em Westminster 59 . Por razões que não estão claras, o procedimento não foi aplicado em todos os órfãos, mas somente em cinco deles. Depois disso, a princesa pediu aconselhamento a Hans Sloane sobre a inoculação de suas próprias filhas. Embora o neto de Sloane tivesse passado pela operação, o médico não tomou para si a responsabilidade de influenciar a decisão de Carolina. Ainda assim, a princesa solicitou que Maitland inoculasse suas duas filhas ${ }^{60}$.

O ano de 1722 foi especialmente relevante para o debate sobre a inoculação na Inglaterra em virtude dos muitos textos publicados. Para situarmos o papel desempenhado por Mary Montagu nesse momento controverso, é preciso antes destacar os panfletos escritos por outros três personagens empenhados nesse debate, e cuja atuação estava diretamente ligada à prática médica. O primeiro texto tinha como autor um dos grandes partidários da inoculação, isto é, o já citado cirurgião escocês Charles Maitland. Contra o uso de tal método, destacavam-se os escritos do médico William Wagstaffe e do boticário Isaac Massey. No intervalo de publicação entre estes dois últimos panfletos, vinha a público um artigo em defesa da inoculação. O escrito era de Lady Mary, mas não exibia o nome da autora.

Logo em fevereiro de 1722, Charles Maitland publicava um texto para responder a objeções surgidas em relação ao experimento de Newgate. Como ele alertava, haviam aparecido muitas informações que eram "frequentemente contraditórias" ${ }^{1}$. Diante disso, ele escrevia com a intenção de levar a público um "relato claro e honesto da verdade dos fatos" ${ }^{2}$. Nessa primeira edição, Maitland citava a experiência de Lady Mary sobre a inoculação no Império Otomano, embora não colocasse expressamente o seu nome. Ademais, ressaltava que o método proposto por ele era aquele observado na Turquia, sem "enfeites de erudição ou de eloquência" 63 .

O sucesso obtido no experimento com prisioneiros de Newgate e com os órfãos da paróquia de St. James estava longe de convencer a comunidade médica sobre a segurança do método. Além disso, um episódio ocorrido em abril de 1722 serviria para aumentar a oposição contra a inoculação e pesaria contra os esforços de Mary Montagu. O filho de um nobre inglês, o senhor Sunderland, morreu enquanto se recuperava do procedimento de inoculação. Embora os defensores do método apontassem estatísticas que demonstrassem a eficácia da inoculação $0^{64}$, foi justamente nos meses seguintes a essa morte que se multiplicaram as vozes contrárias ao método de proteção contra a varíola.

Em junho desse ano, vinha a público o panfleto possivelmente mais feroz contra a aplicação da inoculação e contra seus principais defensores, dentre estes, Charles Maitland e Mary Montagu. O médico inglês William Wagstaffe (1685-1725) escreveu um texto em que exibia já no título o "perigo e incerteza de inocular a varíola". Na capa, o autor indicava também suas credenciais: doutor em medicina, membro do College of Physicians e da Royal Society, e médico do prestigioso hospital St. Bartholomew ${ }^{65}$.

${ }^{59}$ GRUNDY, 1999, op. cit. p. 213.

${ }^{60}$ GRUNDY, 1999, op. cit. p. 214

${ }^{61}$ MAITLAND, C. Mr. Maitland's account of inoculating the small pox. London, printed for the author, by J. Downing: and to be sold by J. Roberts, 1722, p. 1.

${ }^{62}$ MAITLAND, 1722, op. cit. p. 1.

${ }^{63}$ MAITLAND, 1722, op. cit. p. 3.

${ }^{64}$ No início de 1720, o médico inglês James Jurin (1684-1750) fez um amplo estudo sobre as taxas de mortalidade em decorrência da doença e da inoculação. A sua conclusão foi que a taxa de mortalidade da varíola era "aproximadamente 1 em 6 (17 por cento) e que menos de 2 por cento morriam como resultado direto da inoculação da varíola" Cf. WOODS, R. Death Before Birth: Fetal Health and Mortality in Historical Perspective. Oxford: Oxford University Press, 2009, p. 223.

${ }^{65}$ WAGSTAFFE, W. A letter to Dr. Freind shewing the danger and uncertainty of inoculating the Small Pox. London: Printed for Samuel Butler next Bernard's Inn in Holborn, 1722. 
Por ser médico, é certo que Wagstaffe indicou em seu panfleto objeções do ponto de vista técnico, ao lado de argumentos que ressaltavam o valor da experiência. A esse respeito, ele afirmava que os médicos não deveriam encorajar tal procedimento, pois este não se sustentava suficientemente na razão ou no fato ${ }^{66}$. Ele defendia que dificilmente um quarto dos inoculados tinha uma "verdadeira e genuína varíola" 67 . Wagstaffe questionava ainda a "natureza" do fluido que se inseria na pessoa a ser inoculada e as consequências que isso poderia gerar ${ }^{68}$. Contudo, as críticas mais duras ao método de inoculação se assentavam em afirmações valorativas de várias ordens.

O médico lamentava que tal método, "praticado apenas por umas poucas mulheres ignorantes" (grifo do autor), em uma região de "pessoas iletradas e irreflexivas", tivesse sido adotado em uma das "nações mais polidas do mundo" 69 . Além de afirmar que o sangue daqueles que viviam no Império Otomano - não citado nominalmente em seu texto - tinha abundância de "partículas mais suscetíveis de inflamação", Wagstaffe sustentava que a "matéria purulenta" misturada com o sangue inglês parecia um pouco repugnante à razão deste último povo ${ }^{70}$. Embora o médico não mencionasse o nome de Mary Montagu, é provável que uma passagem de seu panfleto fosse referência a ela e a outros médicos defensores da inoculação. No trecho em questão, Wagstaffe criticava "alguns otimistas viajantes da Turquia" que, por meio de "rumores e relatos, estavam aficionados em abordar a inoculação" 71 .

Nesse sentido, o discurso de Wagstaffe foi apontado por Isobel Grundy como assentado mais na "classificação, nação e raça do que no profissionalismo" 72 . Em seu texto, havia um julgamento que desconsiderava o método de inoculação por duas grandes razões: tratava-se de um recurso médico cujas origens remetiam ao Levante - um local visto como atrasado pelos europeus em termos de ideias e práticas médicas - e, de forma ainda mais enfática, era realizado e defendido por mulheres, o que desqualificava as atribuições de tal operação, uma vez que as mulheres - fossem na Europa ou no Levante - não faziam parte da comunidade médica.

Em 25 de setembro, era a vez do boticário Edmund Massey se levantar contra a inoculação. Num texto sucinto, dedicado ao médico Hans Sloane, Massey deixava indicado logo na capa a quem ele se opunha: o cirurgião Charles Maitland. Assim como Wagstaffe, Massey desqualificava o método completamente, encarando-o como uma prática antinatural e mesmo uma doença. Para ele, o termo "inoculação" deveria ser substituído por "encantamento" "73. Era justamente na parte final do panfleto que Massey se dedicava a atacar o autor de um artigo publicado poucos dias antes. Tratava-se do texto anônimo de Mary Montagu.

Robert Halsband acredita que o ataque de Wagstaffe à prática da inoculação feita por "mulheres ignorantes" tenha irritado Montagu a ponto de incitar uma defesa pública do método $^{74}$. Foi em artigo publicado em 13 de setembro de 1722 no jornal Flying-Post que Lady Mary expressaria não apenas a defesa da inoculação, mas também seu descontentamento com a forma como tal procedimento era adotado pelos médicos ingleses. $\mathrm{O}$ autor imaginado por Montagu -

\footnotetext{
${ }^{66}$ WAGSTAFFE, 1722, op. cit. p. 4.

${ }^{67}$ WAGSTAFFE, 1722, op. cit. p. 17.

${ }^{68}$ WAGSTAFFE, 1722, op. cit. p. 4.

${ }^{69}$ WAGSTAFFE, 1722, op. cit. p. 5-6.

${ }^{70}$ WAGSTAFFE, 1722, op. cit. p. 11.

${ }^{71}$ WAGSTAFFE, 1722, op. cit. p. 36.

${ }^{72}$ GRUNDY, 1994, op. cit. p. 16.

${ }^{73}$ MASSEY, I. A Short and Plain Account of Inoculation: With Some Remarks on the Main Arguments made use of to recommend that Practice, by Mr. Maitland and others. London: Printed for W. Meadows, at the Angel in Cornhill, and Soid by T. Payne in Pater Noster Row, 1722, p. 20.

${ }^{74}$ HALSBAND, 1953, op. cit. p. 400.
} 
um comerciante - exibia, assim como ela, a autoridade de quem havia testemunhado tal prática em terras turcas.

Contudo, antes de vir a público, o texto escrito por Mary Montagu passaria pelo crivo do editor e teria termos e ideias modificados ou simplesmente banidos. O editor eliminou todas as "críticas e sarcasmo contra os médicos" feitos pela autora e, no geral, "suavizou seu tom indignado e apaixonado" 75 . As alterações começavam já no título. Contra a opção de Mary Montagu em escrever sobre a inoculação da varíola de modo geral, o editor optou por indicar que o relato era sobre a inoculação em Constantinopla ${ }^{76}$. Entre as mudanças operadas no artigo, estava a substituição da palavra "médicos", na expressão "desonestidade e ignorância dos médicos", por "algumas pessoas"; no lugar de sua crítica "à infame prática" feita na Inglaterra - dadas as muitas alterações inseridas no método pelos médicos -, o editor indicava apenas que tal deturpação ocorria em alguns lugares; a palavra sucesso, atrelada a esse procedimento, era omitida.

Uma das principais críticas de Montagu se referia aos "preparativos" adotados por certos médicos ingleses, cujo emprego ocorria antes da inoculação. A autora punha em dúvida se as "purgações ou qualquer método violento" - como a flebotomia - realmente levavam o corpo a um temperamento moderado. Para ela, uma "dieta fresca" e "sono regular" eram suficientes para alcançar esse estado. Na sequência, a autora criticava frontalmente a Faculdade de Medicina de Londres - o College -, afirmando: "como eu não sou membro da Faculdade, eu não pretendo disputar com estes senhores acerca de sua prática geral em outros distúrbios"77. Mas ela defendia que esses médicos deveriam considerar o seu testemunho em Constantinopla e, portanto, a sua afirmação de que os "longos preparativos servem apenas para destruir a força do corpo necessária para eliminar a infecção" 78 . Esse trecho também sofreu interferência do editor, uma vez que a referência à faculdade foi suprimida.

O que Mary Montagu defendia nesse artigo era a adoção do método "turco" de inoculação, tal como ela e outros estrangeiros haviam presenciado no Levante. Em outras palavras, o procedimento deveria ocorrer através de uma "picada de agulha, a menor quantidade possível de matéria de varíola e sem preparação ou acompanhamento além da moderação do senso comum"79. Ainda que Lady Mary falasse a partir de sua própria experiência e em termos internos à área médica, as suas palavras, mesmo anônimas, continuavam provocando desconfiança. Para o boticário Isaac Massey, o artigo do Flying-Post havia sido escrito por um "falso comerciante na Turquia" $"$. Os seus argumentos médicos, de outro modo, sequer seriam discutidos por Massey.

\section{Conclusão}

A experiência da doença gera como consequência o temor por seus efeitos e o esforço para remediar e, de maneira mais urgente, evitar o seu aparecimento. Isso era uma preocupação especialmente recorrente para as vítimas da varíola, doença epidêmica na Europa ainda no período moderno ${ }^{81}$. No século XVII, um provérbio alemão afirmava que "poucos permaneciam

\footnotetext{
${ }^{75}$ HALSBAND, 1953, op. cit. p. 400.

${ }^{76} \mathrm{O}$ título original era "A Plain Account of the Inoculating of the Small Pox by a Turkey Merchant" e foi impresso como "An account of the inoculating the small pox at Constantinople, by a Turky-Merchant" Cf. HALSBAND, 1953, op. cit. p. 401-402.

${ }^{77}$ HALSBAND, 1953, op. cit. p. 402.

${ }^{78}$ HALSBAND, 1953, op. cit. p. 402.

${ }^{79}$ GRUNDY, 1999, op. cit. p. 217.

${ }^{80}$ MASSEY, 1722, op. cit. p. 20.

${ }^{81}$ Sobre isso, ver HOPKINS, D. R. The Greatest Killer. Smallpox in History. Chicago and London: The University of Chicago Press, 2002.
} 
livres do amor e da varíola" 82 . No século seguinte, depois de contínuos surtos da doença em Londres, Charles Maitland comparava a varíola a um "anjo destruidor" 83.

Diante desse cenário, é certo que soluções seriam buscadas e, ao mesmo tempo, os possíveis problemas trazidos por elas seriam apontados. No caso da inoculação, muitos médicos europeus se opunham ao método num primeiro momento em razão da novidade do procedimento - e, portanto, da incerteza de sua eficácia. Contudo, as justificativas empregadas contra a adoção do procedimento estavam longe de ser puramente médicas.

No grupo dos opositores, a desqualificação dessa técnica abarcou uma série de alegações alheias ao domínio científico. Se ela foi tomada como antinatural pelo boticário Isaac Massey, o reverendo Edmund Massey não apenas a considerava ilegal, como "diabólica". Não sem razão, o seu texto se intitulava "Um sermão contra a prática perigosa e pecaminosa da inoculação" 84 . Mas nenhuma característica poderia produzir maior impacto do que a gênese da inoculação: suas origens estrangeiras e femininas eram obstáculos incontornáveis para muitos médicos europeus. Como escreveu Isobel Grundy, foram “os oponentes da nova prática que colocaram ênfase tanto em sua origem oriental ou islâmica e em suas associações femininas" ${ }^{25}$.

Assim como os outros partidários do método, Mary Montagu defendia sua utilização amparando-se na experiência e na razão. Desse modo, a inoculação seria uma oportunidade de se "aplicar métodos empíricos de filosofia natural para uma matéria de importância social e para a demonstração de que esses métodos tinham utilidade prática" ${ }^{\text {" }}$. Entretanto, embora a sua atitude em relação à inoculação fosse moldada pelos "valores sociais e epistemológicos da nova ciência" 87 , isso não foi impeditivo para o questionamento de seus conhecimentos práticos. A sua experiência no Levante não foi apenas refutada, mas completamente esvaziada de sentido pelos médicos e outros homens que se opunham à inoculação.

Além de defender a inoculação entre os membros da aristocracia inglesa, alcançando inclusive representantes da família real, Lady Mary ousou discordar até mesmo dos médicos ingleses que alteravam o método oriental. O que ela proclamava era o emprego do método padronizado, sem espaço para inúmeras interferências médicas projetadas para cada paciente. Lembremos que na década de 1720, quando a operação passou a ser realizada na Inglaterra, os médicos inseriram inúmeras modificações no procedimento, concedendo um espaço de atuação para si próprios inexistente na sociedade islâmica ${ }^{88}$.

Considerando a forma como a escritora inglesa advogou a inoculação da varíola, é possível afirmar que sua função se estendia para além da mera defesa da operação. Mary Montagu demonstrava conhecimento a respeito de seu funcionamento e de seus resultados. A sua descrição sobre a prática do método - ou, como chamou Narin Hassan, desse "ritual nativo" - indica "um tom de autoridade científica e detalhe", além de revelar as "metodologias específicas da

${ }^{82}$ HOPKINS, 2002, op. cit. p. 32.

${ }^{83}$ GRUNDY, 1999, op. cit. p. 209

${ }^{84}$ MASSEY, E. A Sermon against the Dangerous and Sinful Practice of Inoculation. Preach'd at St. Andrew's Holborn, on Sunday, July the 8th, 1722. The third edition. London: Printed for William Meadows, at the Angel in Cornbill, 1722 , p. 15.

${ }^{85}$ GRUNDY, 1994, op. cit. p. 16.

${ }^{86}$ HALPERN, S. A. Lesser Harms: The Morality of Risk in Medical Research. Chicago/London: The University of Chicago Press, 2004, p. 20.

${ }^{87}$ CAPOFERRO, R. Genre Contamination and Gender Critique in Lady Mary Montagu's Turkish Embassy Letters. In: D'EZIO, M. (ed.). Literary and Cultural Intersections during the Long Eighteenth Century. Newcastle: Cambridge Scholars Publishing, 2008, p. 50.

${ }^{88} \mathrm{Em}$ virtude de sua formação acadêmica e, portanto, de seus conhecimentos sobre os humores, os médicos possuíam monopólio para indicar os preparativos e para acompanhar o paciente depois da inoculação. Tratava-se de uma forma de manter uma função exclusiva nesse processo e também de manter sua posição no topo da categoria médica. Sobre isso, ver BRUNTON, 1990, op. cit. p. 1-33. 
inoculação turca"89. King-Thom Chung vai além, ao afirmar que a iniciativa de Montagu na disseminação do método não apenas "levou ao trabalho de Edward Jenner com varíola bovina", mas também à "teoria do germe de Louis Pasteur (1822-1895) e de Robert Koch (18431910)"90.

Embora tenha recebido alguns elogios por seu papel na defesa e disseminação da inoculação ${ }^{91}$, é preciso lembrar as dificuldades e preconceitos enfrentados por ela quando decidiu pela inoculação de seus dois filhos. Lady Mary deixaria registrado o desprezo de enfermeiras e servas, e a hostilidade de tias e avós contrárias ao procedimento realizado em sua filha. Não faltaria quem a acusasse de ser uma "mãe desnaturada" que havia colocado a vida de seus filhos em risco ${ }^{92}$. A sua influência entre familiares e amigos também não foi conquistada rapidamente. Lady Mary não conseguiu convencer uma das irmãs a inocular seu filho. O sobrinho morreu em 1723 em decorrência da doença ${ }^{93}$. Sua amiga Sarah Chiswell, a destinatária da "Carta XXXI", também morreu atingida pela varíola, em 1726. Lembremos que até mesmo defensores do método buscavam esconder as origens feminina e oriental da inoculação ${ }^{94}$. Diante de todas essas evidências, não há como discordar de Bernardette Andrea quando ela afirma que Lady Mary enfrentou uma "reação sexista, racista e orientalista" no seu próprio país".

Por fim, o episódio envolvendo Mary Montagu e a proposição de uma técnica oriental no interior de uma comunidade médica e masculina levanta a necessária discussão sobre o lugar social ocupado pelas mulheres. Como escreveu Isobel Grundy, "o caso de Lady Mary demonstra o quão difícil é localizar qualquer contribuição para o avanço científico fora das instituições de ciência, nas ações de indivíduos excluídos por gênero, raça, classe ou educação"96. O fato é que a escritora inglesa condensava a presença de elementos inaceitáveis para o establishment médico da época: era porta-voz de um método praticado no Império Otomano - local considerado atrasado pelos europeus -; não possuía formação médica, o que a impedia de participar dos debates em tais círculos; e, talvez, o principal, era mulher.

${ }^{89}$ HASSAN, N. Diagnosing Empire: Women, Medical Knowledge, and Colonial Mobility. Aldershot and Burlington, VT: Ashgate, 2011, p. 23.

${ }^{90}$ CHUANG, K-T. Women Pioneers of Medical Research: Biographies of 25 Outstanding Scientists. Jefferson: McFarland \& Company, 2010, p. 14.

${ }^{1}$ Aaron Hill, em The Plain Dealer, e o filósofo francês Voltaire, em suas Cartas escritas de Londres, prestaram homenagens à Lady Mary. Mas é importante lembrar que os dois autores mencionavam a função da inoculação em proteger a beleza feminina Cf. HALSBAND, 1953, op. cit. p. 404.

92 GRUNDY, 1999, op. cit. p. 212.

${ }^{93}$ HASLBAND, 1953, op. cit. p. 403.

${ }^{94}$ GRUNDY, 1999, op. cit. p. 212.

${ }^{95}$ ANDREA, B. Alternatives to Orientalism?: Mary Wortley Montagu and Her ‘Turkish’ Son. In: MACLEAN, G. (ed.). Britain and the Muslim Word: Historical Perspectives. Newcastle: Cambridge Scholars Publishing, 2011, p. 118.

${ }^{96}$ GRUNDY, 1994, op. cit. p. 16. 